\title{
Quality of the Reference of the Obstetric Emergencies to the Departmental Hospital Center of Borgou (CHD/B) at Parakou (Benin)
}

\author{
Obossou AAA ${ }^{1 *}$, Salifou $K^{1}$, Hounkpatin $B^{2}$, Tshabu Aguemon $A^{2}$, Tossou $\mathbf{N}^{1}$, Gounongbe $\mathrm{F}^{1}$ and Perrin $\mathbf{R X}^{2}$
}

${ }^{1}$ Mother-Child Department, Faculty of Medicine; University of Parakou, Republic of Benin

${ }^{2}$ Faculty of Health Sciences, University of Abomey calavi, Republic of Benin

\begin{abstract}
Objective: To estimate the quality of the obstetric references of the peripheral sanitary trainings of the department of Borgou to the departmental hospital center (CHD/B).

Methodology: It was about a descriptive and analytical transverse study realized from 01 March to May 31 st 2013. We considered the sociodemographic data, the elements of the preparation and the transport of the reference were taken into account, and finally maternal and neonatal prognosis.

Results: The frequency of the referred women was $34,6 \%$. The average age of the referred women was $25 \pm 5,7$ years old with extremes from 15 years to 44 years. The preparation of the reference was poor quality in $37,3 \%$ of the cases. An index card of standardized reference was used only in $57,3 \%$. Transporting patients of the periphery in the center of reference was poor quality in $70 \%$ of the cases. The transport was made by a way other than an ambulance in $69,6 \%$ of the cases. The woman was accompanied by an agent of health in $15 \%$ of the cases. The venous access was taken in $75.4 \%$ of cases. The CHD/B was alerted before the reference only in $7,3 \%$ of the cases. $80 \%$ of the maternal deaths arose among the women referred to the sanitary trainings for an obstetric urgency.
\end{abstract}

Conclusion: The quality of the preparation significantly influence maternal prognosis. This raises the need for an evaluation and revitalization of our reference systems

\section{Keywords: Obstetric urgency; Reference; Quality}

Abbreviations: CHD/B: Departmental of Borgou Hospital Center; WHO: World Health Organization; UNFPA: United Nations Fund for Population Activities; SONU: Obstetrical and Neonatal Care Emergency; BEST-SD: Office for Studies and Support for New Technologies in Health and Development); CUGO: University Clinic of Gynecology and Obstetrics

\section{Introduction}

According to the World Health Organization (WHO), 200 million women become pregnant each year worldwide. Of these, 287,000 die from complications of pregnancy, childbirth and postpartum. A significant portion of these deaths (99\%) is recorded in developing countries. These deaths registered in developing countries, the Africa in the South of Sahara totals 50\% [1]. In Benin, the maternal mortality ratio was estimated at 397 deaths for 100,000 live births in 2011 [2]. Maternal death is partly dependent on the level of socio-health organization. This organization is partly dependent on the system put in place to refer patients to referral centers where needed. So we wanted to assess the quality of this instrument of complementarily between the different levels of the health pyramid: The reference. This study aims at the inventory of obstetric referrals in a health district.

\section{Patients and Methods}

This was a cross-sectional descriptive and analytical study conducted from 01 March to 31 May 2013 and it took place in the department of gynecology and obstetrics of departmental hospital center of Borgou in Parakou.

The study population consisted of women pregnant, in childbirth labor and puerperal of the peripheral maternity referred to the $\mathrm{CHD} / \mathrm{B}$. It was a comprehensive sampling that had included all women pregnant, in childbirth labor and puerperal referred from the peripheral maternity public and private to the maternity of $\mathrm{CHD} / \mathrm{B}$. All those whose files did not contain the reference data were excluded.

In order to assess the quality of the preparation of the references we have already defined the essential criteria for adequate preparation of the reference. A weighting of the criteria was made. Two points were systematically assigned to all criteria. A coefficient of 3 to 5 according to the important criterion was then added to each criterion. The maximum possible score for the quality of the preparation of a reference is 100 . Three levels of quality of preparation of the reference were determined by scores. Note $\leq 50$ corresponds to poor quality of the preparation of the reference. When the note is $>50$ and $\leq 75$, the quality of the preparation of the reference is deemed well enough; while a score $>$ 75 corresponds to a good quality of preparation of the reference. The same approach was used to assign points to the variables relating to the conditions of transport. The quality of the transport is referred to and denoted 32 .

Two quality levels: good and bad, have been determined. Scores $\leq$ 19 correspond to a poor quality of transport while those from 20 to 32 correspond to a good quality of transport referred (see criteria for good conditions of transport in the appendix).

*Corresponding author: Obossou Awadé Afoukou Achille, Mother-Child Department, Faculty of Medicine, University of Parakou, 03 PO. Box: 18, Republic of Benin, Tel: 229-958-532-79; E-mail: awadefr2000@yahoo.fr

Received September 22, 2014; Accepted December 01, 2014; Published December 03, 2014

Citation: Obossou AAA, Salifou K, Hounkpatin B, Tshabu Aguemon A, Tossou $N$, et al. (2014) Quality of the Reference of the Obstetric Emergencies to the Departmental Hospital Center of Borgou (CHD/B) at Parakou (Benin). Clinics Mother Child Health 11: 168. doi: 10.4172/2090-7214.1000168

Copyright: ( 2014 Obossou AAA, et al. This is an open-access article distributed under the terms of the Creative Commons Attribution License, which permits unrestricted use, distribution, and reproduction in any medium, provided the original author and source are credited. 
Citation: Obossou AAA, Salifou K, Hounkpatin B, Tshabu Aguemon A, Tossou N, et al. (2014) Quality of the Reference of the Obstetric Emergencies to the Departmental Hospital Center of Borgou (CHD/B) at Parakou (Benin). Clinics Mother Child Health 11: 168. doi: 10.4172/20907214.1000168

Page 2 of 4

Data collection was performed using a card counting records

The variables studied were:

- The Social demographic characteristics of women referred (age, occupation, gender)

- The preparation of the reference

- Transport conditions

- Maternal and neonatal prognosis.

Processing and data analysis were performed using Epi Info 2008 Software Version 3.5.1. The data were organized in tables and figures using Excel software. Test $\mathrm{X}^{2}$ Pearson was used to calculate the differences with a significance level of $5 \%$.

\section{Results}

\section{Social demographic characteristics referred women}

The survey focused on 260 women referred for 752 admissions in our study with a frequency of $34.6 \%$. The average age of those referred was $25 \pm 5.7$ years, ranging from 15 years to 44 years. Household predominated at $37.7 \%$ followed by vendors- saleswoman $(24.6 \%)$; artisans (19.6\%); pupils/students (13.5\%) and staff (4.6\%). Our patients are illiterates for $39.2 \%$ of cases; had a primary level for $26.5 \%$; secondary level for $28.8 \%$ and $5.5 \%$ in a higher level. They came for $88.5 \%$ of cases in the town of Parakou. They were nulliparous in $45 \%$; paucipares $36.5 \%$ and $18.5 \%$ multiparous.

\section{Reference preparation}

The quality of the preparation of the reference: Reference Sheet was used for 149 women with $57.3 \%$ of respondents, and the health record in 53 patients (20.3\%). 58 patients (22.3\%) were referred without support. By weighting the elements of preparation recorded on the reference cards, we got the quality of the preparation of the reference. The quality of the preparation of the reference is shown in Table 1.

Quality of preparation of the reference and health facilities: Table 2 shows the distribution of health facilities according to the quality of the preparation of the reference. Private health facilities had a proportion of poor preparation of the reference (44.6\%) about three times more than public health facilities (16.8\%)

Quality preparation of the reference and life-threatening breast: Ten (10) maternal deaths were recorded at the maternity $\mathrm{CHD} / \mathrm{B}$ during the study period. Eight (8) of the 10 women dead were referred from peripheral health facilities for obstetric emergencies. Table 3 shows the quality of preparations references and outcome of the care of the women surveyed. There is a statistically significant relationship between the quality of the preparation of the reference and the outcome of the treatment of women referred.

Quality of preparation of the reference and childbirth death: There were $28.6 \%$ of deaths before or after childbirth for 70 women when the preparation of the reference was bad and $24.8 \%$ of deaths before or after childbirth for 98 women including the preparation of the reference has been good with no statistically significant difference.

Transport quality: For 260 references, an ambulance was used for 7 references so $2.7 \%$, firefighters were requested for $27.7 \%$ of cases and unconventional transport for $69.6 \%$ (motorcycle: $51.5 \%$ vehicles transit: $18.1 \%)$

Motherhood of CHD/B was alerted 19 times before the arrival of the reference for $7.3 \%$ of cases. The woman was accompanied by a health worker for $15 \%$ of cases. The venous access was taken in $75.4 \%$ of cases. By weighting our transport criteria, we found that the quality was good in $30 \%$ and poor in $70 \%$ of cases.

Quality of transport and health training: Table 4 presents the distribution of health facilities according to the quality of transport. There is a statistically significant relationship between the type of women's home facility and the quality of transport in references

Quality of transport and management of mother: Table 5 shows the distribution of women referred by the outcome of their care based on the quality of transport. A statistically significant relationship between the quality of transport of women in the references and after the treatment has not been demonstrated.

\begin{tabular}{|c|c|c|}
\hline Quality of the preparation reference & Number & $\%$ \\
\hline Bad & 97 & 37,3 \\
\hline Fairly & 57 & 21,9 \\
\hline Good & 106 & 40,8 \\
\hline Total & 260 & 100 \\
\hline
\end{tabular}

Table 1: Distribution of women referred by the quality of the preparation of the reference.

\begin{tabular}{|c|c|c|c|c|c|c|c|c|}
\hline \multicolumn{10}{|c|}{ Reference of preparation } \\
\hline \multirow{2}{*}{$\begin{array}{c}\text { Health } \\
\text { facilities }\end{array}$} & \multicolumn{2}{|c|}{ Poor } & \multicolumn{2}{|c|}{ Fairly well } & \multicolumn{2}{c|}{ Good } & \multicolumn{2}{c|}{ Total } \\
\cline { 2 - 10 } & $\mathrm{N}$ & $(\%)$ & $\mathrm{N}$ & $(\%)$ & $\mathrm{N}$ & $(\%)$ & $\mathrm{N}$ & $(\%)$ \\
\hline private & 41 & $(44,6)$ & 25 & $(27,2)$ & 26 & $(28,3)$ & 92 & $(100)$ \\
\hline public & 22 & $(16,8)$ & 31 & $(23,7)$ & 78 & $(59,5)$ & 131 & $(100)$ \\
\hline
\end{tabular}

$\mathrm{Chi}^{2}=26,3586 \mathrm{ddl}=2 \mathrm{P}=<<<0,05$

Table 2: Distribution of health facilities according to the quality of the preparation of the reference.

\begin{tabular}{|c|c|c|c|c|c|c|}
\hline \multirow{2}{*}{$\begin{array}{c}\text { Quality of the } \\
\text { Preparation reference }\end{array}$} & \multicolumn{6}{|c|}{ Maternal Deaths } \\
\cline { 2 - 7 } & $\mathbf{2}$ & Yes & \multicolumn{2}{c|}{ No } & \multicolumn{2}{c|}{ Total } \\
\hline bad & 7 & $(7,4)$ & 88 & $(92,6)$ & 95 & $(100)$ \\
\hline $\begin{array}{c}\text { Fairly } \\
\text { well }\end{array}$ & 1 & $(1,8)$ & 55 & $(98,2)$ & 56 & $(100)$ \\
\hline good & 0 & $(0,0)$ & 105 & $(100)$ & 105 & $(100)$ \\
\hline
\end{tabular}

$\mathrm{Chi}^{2}=9,369 \mathrm{ddl}=2 \mathrm{p}=0,0092<0,05$

Table 3: Distribution of women referred by the outcome of their care based on the quality of the preparation of the reference.

\begin{tabular}{|c|c|c|c|c|c|c|}
\hline \multirow{2}{*}{$\begin{array}{c}\text { Clinic } \\
\text { original }\end{array}$} & \multicolumn{2}{|c|}{ Good } & \multicolumn{2}{|c|}{ Bad } & \multicolumn{2}{c|}{ Total } \\
\cline { 2 - 7 } & $\mathbf{N}$ & $\%$ & $\mathbf{N}$ & $\%$ & $\mathbf{N}$ & $\%$ \\
\hline private & 109 & $(84,5)$ & 20 & $(15,5)$ & 129 & $(100)$ \\
\hline Public & 73 & $(55,7)$ & 58 & $44,3)$ & 131 & $(100)$ \\
\hline
\end{tabular}

$\mathrm{Chi}^{2}=25,6198 \mathrm{ddl}=2 \mathrm{p}=0,0000$

Table 4: Distribution of health facilities according to the quality of transport ( $N=$ 260)

\begin{tabular}{|c|c|c|c|c|c|c|}
\hline \multirow{2}{*}{$\begin{array}{c}\text { Quality of } \\
\text { transport }\end{array}$} & \multicolumn{3}{|c|}{ Maternal death } \\
\cline { 2 - 8 } & $\mathbf{2}$ & \multicolumn{2}{|c|}{ No } & \multicolumn{2}{c|}{ Total } \\
\hline Bad & 8 & $(4,4)$ & 174 & $(95,6)$ & 182 & $(100)$ \\
\hline Good & 0 & $(0,0)$ & 78 & $(100)$ & 78 & $(100)$ \\
\hline
\end{tabular}

$\mathrm{Chi}^{2}=3,537 \mathrm{ddl}=2 \mathrm{p}=0,06$

Table 5: Distribution of women referred by the outcome of their care based on the quality of transport $(N=260)$. 
Citation: Obossou AAA, Salifou K, Hounkpatin B, Tshabu Aguemon A, Tossou N, et al. (2014) Quality of the Reference of the Obstetric Emergencies to the Departmental Hospital Center of Borgou (CHD/B) at Parakou (Benin). Clinics Mother Child Health 11: 168. doi: 10.4172/20907214.1000168

\section{Discussion}

\section{Frequency-referred}

Women evacuated from surrounding structures represented 34.6\% of admissions at Departmental Hospital of Borgou (CHD/B). This rate is similar to that found by Tshabu-Aguemon et al. [3] to the University Clinic of Gynecology and Obstetrics (CUGO) at Cotonou (30.38\%) in 2011, is lower than those of Cisse et al. [4] to Senegal (46.7\%) in 2003; Zamane et al. [5] to Burkina Faso (44.2\%) in 2012 but higher than those of Sepou et al. [6] in Centrafrique (12\%) in 2009 and Lompo [7] to Burkina Faso (12.3\%) in 1993. Thus the frequency of obstetric referrals varies from one country to another depending on the distribution of health centers in the area and their equipment.

\section{Demographics Data}

The average age of women referred was $25 \pm 5.7$ years, ranging from 15 years to 44 years. Tshabu-Aguemon et al. [3] to Cugo had reached similar results (average age of 26.8 with a range of $15-47$ years). Zamane et al. [5] and Cisse et al. [4] reported respectively a mean age of 25.6 years and 23.5 years in their study populations.

The age group of $20-34$ year olds is the most represented (76.8\%). This result is understandable; this age group is the period of maximum reproductive age. Saizonou et al. [8] had reported in a 2006 study on the treatment of "beautiful escape" referred to seven maternity southern Benin for this age group 64\%, lower than our result.

Majority of Women in $95.4 \%$ has no income or belongs to lowincome strata (household, saleswomen, artisans, pupils/student). They are financially dependent on their spouses who are meeting all medical expenses. This makes it difficult to make the decision for access to care but also to acceptance to go to a referral center where expenses are higher due to the difficulty in meeting the costs when the spouse has income modest Sepou et al. [6] Centreafrique; Lompo et al. [7] in Burkina Faso found more than half of their patients without profession respectively $52.8 \%$ and $58 \%$ of cases.

In these women, the lack of financial income results in late consultations in case of health problems. These women are more exposed to obstetric complications.

About a woman referred in two was nulliparous. Other authors have found similar characteristics. Sepou et al. [6] Centreafrique (2009) published $61.5 \%$ of patients nulliparous or primiparous. For Cisse et al. [4] in Senegal (2003), one third of the patients were primiparous. This high rate of low parity may be explained by the fact that in these women in labor is longer and thus increases the risk of the reference.

\section{Preparation and quality of the reference}

The need for comprehensive data to support the patient for proper continuity of care referral center should make systematic use of the reference sheet. Reference card had been used for $57.3 \%$ of our sample. This result can be explained by ignorance of the staff of the importance of background material in the proper management of women referred.

This finding is recurrent in many African countries. So Zamane et al. [5] found that $78.7 \%$ use the reference sheet at Burkina Faso best than our result.

The quality of the preparation was poor in $37.3 \%$ of cases. This rate is much higher than that of Kongnyuy et al. [9] Malawi, $11.3 \%$ in 2008, but their system was characterized by periodic assessment by clinical audits. Our health care systems should adopt continuous assessments for the improvement of indicators.

The poor quality of the preparation of the reference was about three times higher (44.6\%) in private health facilities in the public (16.8\%). A similar observation was made by the team of Tshabu-Aguemon [3] to Cugo in 2012, which found $54 \%$ of bad reference from private health facilities. This may be related to the low qualifications of providers of maternity private sector for the most part are informal health facilities.

\section{Transport conditions}

The unavailability of the ambulance in the health centers, the limited financial resources of patients and the negative perception (certain death at the end) that have populations of the ambulance, explain the seven women referred with an ambulance, and 181 referred by a means other than an ambulance.

In the literature, Tshabu-Aguemon et al. [3] to Cugo Cotonou; Sepou et al. [6] Centreafrique in 2009, obtained similar results $69.6 \%$ and $68.6 \%$ reference by unconventional means of transport. In Burkina Faso in 2011, Zamane et al. [5] were published 38.5\% benchmarking proportion with other means that ambulance.

Motherhood CHD/B was alerted 19 times (7.3\%) before the arrival of the reference. It could be that the centers do not have a telephone available for the cause. The high rate of private health facilities implies that there is lack of awareness and training on the preparation of the reference to motherhood. The Department of Health and institutions such as Best-SD, WHO, UNFPA often organize training seminars and refresher at the point of service at the north public health facilities on emergency obstetric and neonatal care (EmONC) [10,11]. This would explain the fact that we have observed different behavior in the conditioning pregnant before their transfer. In fact, venous access was taken in $88.5 \%$ of referrals from public health facilities against $62 \%$ came from private health facilities. This result is higher than TshabuAguemon et al. [3] to Cugo (Cotonou) in 2012 which was $62.1 \%$

Eighty-five percent $(85 \%)$ references were carried out without the support of a health workforce. Tshabu-Aguemon et al. [3] and ZAMANE et al. [5] had found $80.5 \%$ and $78.1 \%$ reference without medical assistance respectively.

Ultimately, the delivery was poor quality $182 / 260$ women referred to $70 \%$. These results highlight the poor conditions of reference of patients and show the enormous shortcomings that still exist in our reference systems. Nguebi et al. [12] at the end of their study in 2004 on the assumption of responsibility and referral of obstetric emergencies in Banguy (Central Africa) had argued that the reference system was not performing in Banguy having problems with missing ambulance, waiting staff to accompany patients.

Efforts should be made to improve our systems of reference for the women referred are at greater risk of maternal death

\section{Maternal and neonatal Prognosis}

Eighty percent $(80 \%)$ of pregnant dead were referred from peripheral health facilities with a statistically significant relationship between the quality of the preparation of the reference and the maternal prognosis. The quality of the reference affects the prognosis of evacuees. This finding is similar to those of Tshabu-Aguemon et al. [3] in Benin in 2011 and Cisse et al. [4] in Senegal in 2003 who reported in their study respectively $82.9 \%$ and $73.3 \%$ of deaths maternal report in the referred patients. 
Citation: Obossou AAA, Salifou K, Hounkpatin B, Tshabu Aguemon A, Tossou N, et al. (2014) Quality of the Reference of the Obstetric Emergencies to the Departmental Hospital Center of Borgou (CHD/B) at Parakou (Benin). Clinics Mother Child Health 11: 168. doi: 10.4172/20907214.1000168

Furthermore, there were $28.6 \%$ deaths before or after delivery for 70 patients with the preparation of the reference was poor with no significant difference. Taylor-Smith et al. [13] in their study in the district Kabezi (Burundi) had concluded that a significantly higher risk of early neonatal mortality (OR 1.9, 95\% CI: 1.1-3.2) associated with transfer times of newborns lying.

Solofomalala et al. [14] in 2007 to Madagascar had regained 83\% of maternal deaths among evacuees and $75.5 \%$ of deaths before or after delivery among evacuees. They tied these results to the lack of access to appropriate care, low socio economic, and the difficulties of access in different regions. Governments and communities should increase health policies for effective access to quality health care for maternal and child safety

\section{Conclusion}

References obstetric emergencies are in precarious conditions in our regions. The quality of the preparation significantly influence prognosis breast. We recommend policy makers to engage in ongoing evaluation and revitalization of the reference system-reference against our underdeveloped countries.

\section{References}

1. WHO / AFRO (2004) Roadmap. The African Union is committed to the figh against maternal mortality. Regional Newsletter for Reproductive Health. No. 2.

2. Ministry Of Health of the Republic Of Benin Branch Programming and Prospective. Health Statistics Yearbook 2011.

3. Tshabu Aguemon C, Denakpo J, Adisso S, Mampassi, De Souza J (2012) Maternal and before or after delivery mortality associated with obstetric referrals to the Cugo CNHU-HKM of Cotonou. Anaesthetist Society resuscitation Francophone black Africa 17: 10.
4. Cisse MI, Raad B, Diouf A, Wade F, Moreau JC (2010) Assessment of obstetric evacuation to hospital kolda (Senegal) Afr Med Black 5701: 37-43.

5. Zamane H, Nayaga R, Ouedraogo CMR, Bonane Thieba B, Lankoande J (2013) The relevance of emergency referrals to maternity CHU-YO. Book of Abstracts of the 6th Congress of the Society of Obstetricians and Gynecologists of Burkina (SOGOB). Ouagadougou on 30 and 31 May 2013.

6. Sepou A, Goddot M, Ngbale R, Gaunefet CE, Domande MZ, et al. (2009) Evolution of the frequency and problems with medical evacuations to the service of Obstetric and Gynecology Community Hospital Banguy Clinics in Mother and Child Health 6: 1007-1012.

7. Lompo K, Hutin YJF, Traore G, Fall F, Guillard-Schmid JB, et al. (1993) Morbidity and mortality associated with medical evacuation of obstetric hospital Bobo-Dioulasso, Burkina Faso. Ann Soc belge Med too 73: 153-163.

8. Saizonou J, De Brouwere V, Vangeenderhuysen C, Dramaix-Wilmet M Buekens P, et al. (2006) Audit of the quality of treatment of "near miss" patients in referral maternities in Southern Benin. Sante 16: 33-42.

9. Kongnyuy EJ, Mlava G, van den Broek N (2008) Criteria-based audit to improve a district referral system in Malawi: a pilot study. BMC Health Serv Res 8: 190.

10. Design Office and Support to New Technologies in Health and Development (BEST-SD) (2012) Socio-Sanitaire Experience program and the Swiss Health Support Programme in improving maternal health, 2002-2012.

11. Sayi AD (2010) Managing references and references against a health district First edition, GRES-D, 82 pages.

12. Nguembi F, Nyanza C, Sepou A, Yabeta G, Nali M (2004) Management and referral of obstetric emergencies in health facilities in Bangui, CAR. Black Afr Med 51: 339-344.

13. Tayler Smith K, Zachariah R, Manzi M, Van Den Boogaard W, Nyandwi G, et al (2013) An ambulance referral network access to emergency obstetric Improves and neonatal care in a rural district of Burundi with high Maternal Mortality. Trop Med Int Health 18: 993-1001.

14. Solofomalala GD, Randriamalalaarijaona RT, Rasendramino $\mathrm{MH}$, Ratsivalaka $\mathrm{R}$, Canonne F (2007) Gynecologic obstetric emergencies in the maternity Malagasy district. Tropical Journal of Surgery 1: 67-70. 